\title{
The global challenge of infectious diseases: the evolving role of the National Institutes of Health in basic and clinical research
}

\author{
Anthony S Fauci
}

\begin{abstract}
The US has entered a new period of fiscal restraint. What does this mean for basic research? Anthony Fauci, director of the National Institute of Allergy and Infectious Diseases, discusses the way forward for research scientists in the US.
\end{abstract}

uring the past several decades, advances emanating from basic research, a substantial proportion of it supported by the US National Institutes of Health (NIH), have transformed almost every discipline in the biomedical sciences, including the field of infectious diseases $^{1,2}$. Technical advances in fields such as genomics and proteomics, synthetic chemistry and robotics, computer modeling, molecular and genetic epidemiology, and information technology have yielded unprecedented new insights into disease pathogenesis, host immunity, pathogen virulence, transmission patterns and drug resistance ${ }^{1,2}$. These advances have facilitated the discovery and design of new vaccines, diagnostics, treatments and other interventions that have had an important part in reducing the burden of infectious diseases. For example, the development of more than 20 licensed medications against human immunodeficiency virus (HIV) has greatly reduced HIV-related morbidity and mortality in settings in which these drugs are used ${ }^{1,2}$. The list of vaccine-preventable diseases has grown with the licensure of vaccines against pathogens such as Streptococcus pneumoniae, Haemophilus influenzae type $\mathrm{b}$ and hepatitis A and B viruses, and improved vaccines for pertussis ${ }^{1,2}$. Many other therapeutics and vaccine candidates are

Anthony S. Fauci is with the National Institute of Allergy and Infectious Diseases, National Institutes of Health, Department of Health and Human Services, Bethesda, Maryland 20892-2520, USA. e-mail: (afauci@niaid.nih.gov)

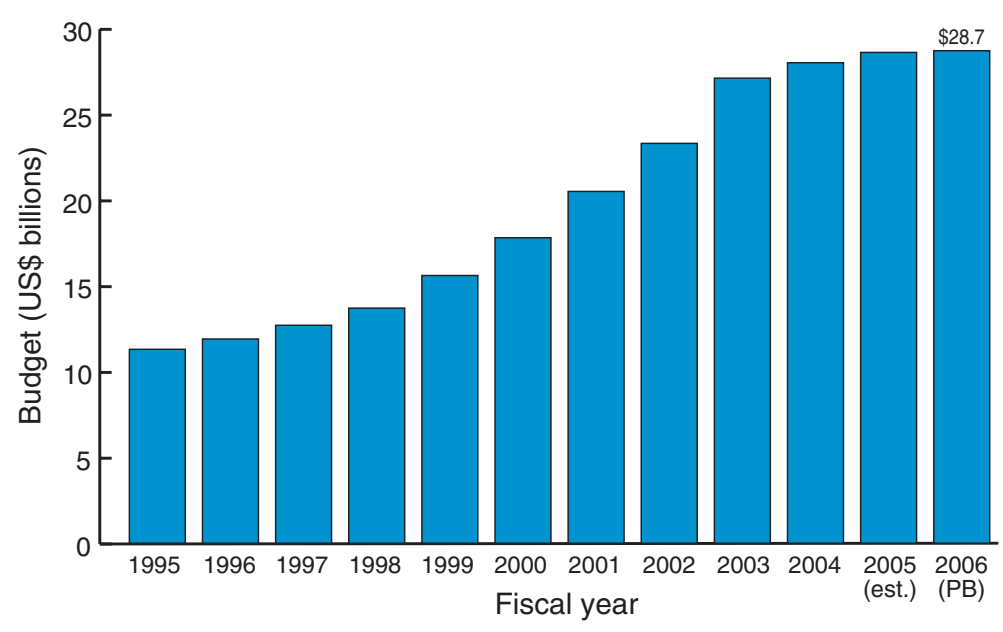

Figure 1 Funding history of the NIH, FY 1995 to FY 2006 (president's budget (PB)). est., estimated.

in the research 'pipeline' to treat and prevent disease caused by both endemic pathogens and emerging and re-emerging microbes such as $\mathrm{H} 5 \mathrm{~N} 1$ avian influenza virus and potential agents of bioterrorism.

The dramatic growth of the science base in infectious diseases began during the 'golden years' of NIH funding in the 1960s, a time when support for the biomedical research community seemed unlimited ${ }^{3}$. A strong momentum was established, and subsequent research advances in areas such as recombinant DNA technology were truly extraordinary, compounding the possibilities for even greater accomplishments. The doubling of the overall NIH budget between fiscal year (FY) 1999 and FY 2003 to $\$ 26.7$ billion provided another big boost (Fig. 1). The NIH FY 2005 budget is about $\$ 28.6$ billion (throughout, budgetary numbers for the $\mathrm{NIH}$ are from the NIH Office of Budget (http://officeofbudget. od.nih.gov/ui/HomePage.htm) and those for the National Institute of Allergy and Infectious Diseases (NIAID) were provided by the NIAID Office of Financial Management (personal communication), except as otherwise indicated).

In terms of budget appropriations, the NIAID, the lead NIH agency for infectious diseases research, has fared even better than the NIH as a whole. In FY 1984, the NIAID was the 


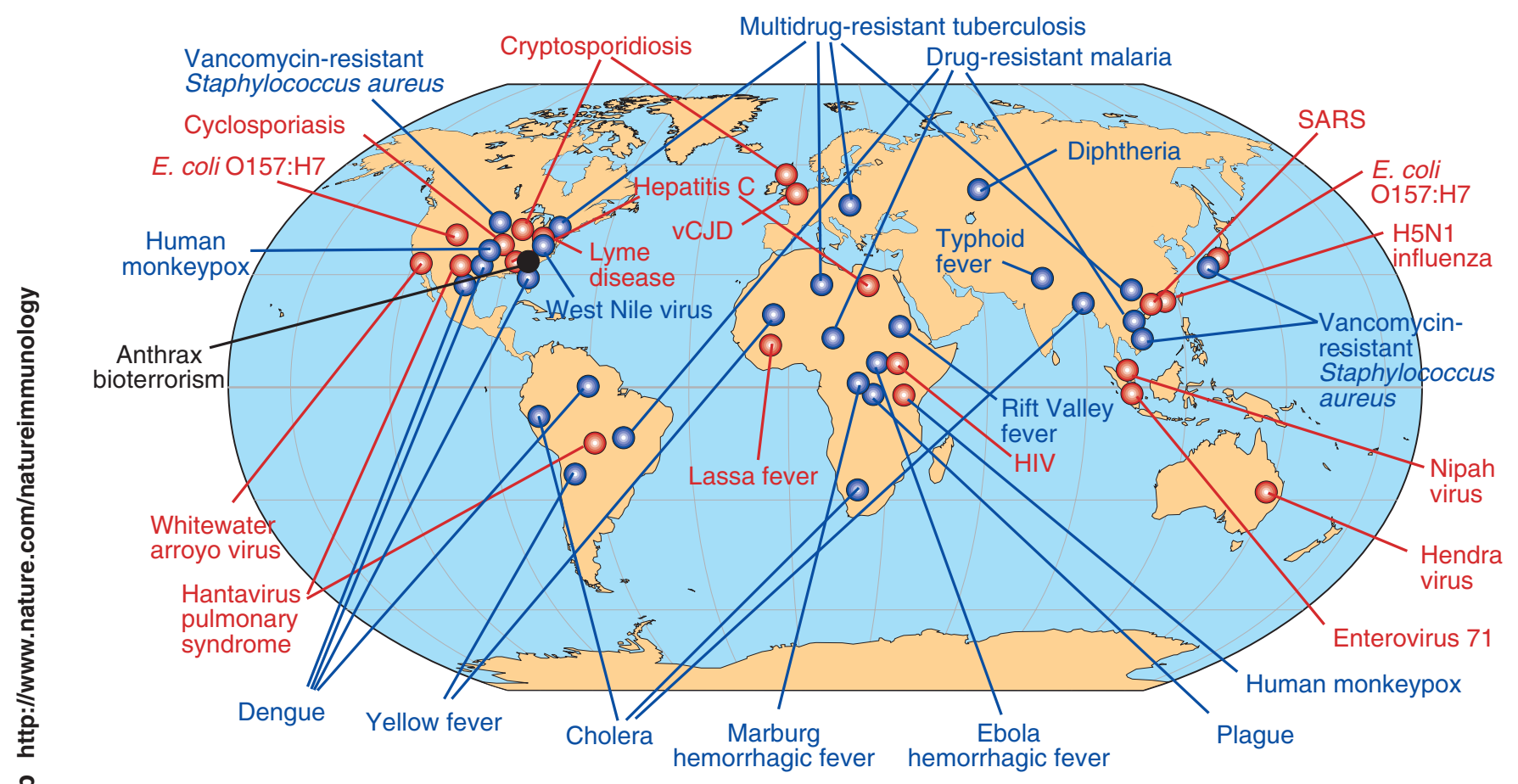

O Newly emerging 0 Re-emerging and/or resurging Deliberately emerging

Figure 2 Global examples of emerging and re-emerging diseases. E. coli, Escherichia coli; vCJD, variant Creutzfeldt-Jakob disease. From ref. 1.

fifth-largest NIH institute in terms of budget (\$319.6 million); in FY 2005, the NIAID is the second-largest NIH institute, with an estimated budget of about $\$ 4.5$ billion.

Much of the budget growth of NIAID can be attributed to large increases in spending on HIV-AIDS, from \$19.6 million in FY 1984 to $\$ 1.5$ billion in FY 2005, and on biodefense research, from \$41.7 million in FY 2001 to \$1.7 billion in FY 2005, and on larger-than-average increases in budget for other emerging and reemerging infectious diseases. Clearly, the infectious diseases research community has fared well in terms of NIH support. Policymakers and taxpayers have recognized that research on global infectious diseases deserves robust support, that it is now axiomatic that we live in a global community and microbes do not recognize borders, and that we must address infectious disease threats regardless of their geographic origin ${ }^{4}$.

HIV-AIDS funding alone, an estimated \$2.9 billion in FY 2005, now comprises more than $10 \%$ of the total NIH budget and approximately one third of the NIAID budget. This increase has not come at the expense of NIH support for other areas of infectious diseases, as increases for non-AIDS infectious diseases and immunology have increased more than the mean increases for the NIH as a whole over the past decade. This level of funding certainly is well justified by the enormity of the medical, public health and societal challenges posed by the HIV-AIDS pandemic. There are unprecedented scientific opportunities to have an effect on the lives of people throughout the world and on the course of the pandemic through an improved understanding of HIV pathogenesis and the development of new or improved approaches to treatment, prevention, care and diagnostics ${ }^{4,5}$.

However, factors are converging that signal a change in the largesse to which biomedical researchers in the US have become accustomed, as the nation collectively 'tightens its belt' to reduce a federal debt projected to exceed $\$ 8$ trillion by the end of FY 2005 (ref. 6). We have entered a new period of fiscal constraint, which has become known as the 'post-doubling' era of the $\mathrm{NIH}^{7}$. All disciplines, including HIVAIDS and other infectious disease as well as other major diseases such as heart disease and cancer, have been affected.

Unlike the approximately 15\% annual increases seen in NIH funding from FY 1999 to FY 2003, the NIH budget increase from FY 2004 to FY 2005 was about 2\%, with the NIAID faring slightly better than the NIH as a whole (Table 1). For FY 2006, the proposed $\mathrm{NIH}$ budget increase is less than $1 \%$ for NIH overall, again with a slightly larger NIAID funding increase ${ }^{8}$ (Table 1). Of note, these projected budget increases do not keep pace with 'biomedical inflation' as represented by the Biomedical Research and Development Price Index ${ }^{9}$; the annual index is projected to increase by about 3.2\% each year from FY 2006 through FY 2009 (ref. 9).

Superimposed on these new budget realities are additional challenges, including the continued emergence and re-emergence of infectious diseases, such as severe acute respiratory syndrome (SARS), West Nile virus and $\mathrm{H} 5 \mathrm{~N} 1$ and other avian influenza viruses with pandemic potential, each of which demands attention and funding ${ }^{1,2}$ (Fig. 2). In addition, there is a growing expectation on the part of the administration, congress and the general public for 'deliverables': countermeasures that can be used in real-world settings to prevent or ameliorate disease. By presidential mandate, research and development of a preventive HIV vaccine and countermeasures against potential agents of bioterror are high priorities for the NIAID $^{8}$.

\section{Past as prologue}

Almost 10 years ago, the NIH was facing an equally sobering budget situation. At the time I wrote that "....resources for biomedical research in general are unlikely to increase substantially in the foreseeable future, and in some areas will be constrained. Yet the opportunities 
Table 1 NIH budget comparison by institute and center

\begin{tabular}{|c|c|c|c|c|c|}
\hline IC & $\begin{array}{c}\text { FY } 2004 \\
\text { Appropriation }\end{array}$ & $\begin{array}{c}\text { FY } 2005 \\
\text { Enacted conference }\end{array}$ & $\begin{array}{c}\text { FY } 2006 \\
\text { President's budget }\end{array}$ & $\begin{array}{c}\text { Change, } \\
\text { FY 2004-FY } 2005\end{array}$ & $\begin{array}{c}\text { Change, } \\
\text { FY 2005-FY } 2006\end{array}$ \\
\hline NIAID & $\$ 4,303,040$ & $\$ 4,402,841$ & $\$ 4,459,395$ & $2.3 \%$ & $1.3 \%$ \\
\hline $\mathrm{NCl}$ & $4,739,445$ & $4,825,258$ & $4,841,774$ & $1.8 \%$ & $0.3 \%$ \\
\hline NHLBI & $2,878,106$ & $2,941,201$ & $2,951,270$ & $2.2 \%$ & $0.3 \%$ \\
\hline NHGRI & 478,828 & 488,608 & 490,959 & $2.0 \%$ & $0.5 \%$ \\
\hline NIDA & 994,605 & $1,006,419$ & $1,010,130$ & $1.2 \%$ & $0.4 \%$ \\
\hline Other ICs & $13,907,113$ & $14,146,550$ & $14,201,359$ & $1.7 \%$ & $0.4 \%$ \\
\hline Subtotal & $27,301,137$ & $27,810,877$ & $27,954,887$ & $1.9 \%$ & $0.5 \%$ \\
\hline NLM & 308,476 & 315,146 & 318,091 & $2.2 \%$ & $0.9 \%$ \\
\hline OD & 327,089 & 358,046 & 385,195 & $9.5 \%$ & $7.6 \%$ \\
\hline$B \& F$ & 98,972 & 110,288 & 81,900 & $11.4 \%$ & $-25.7 \%$ \\
\hline Total & $28,035,674$ & $28,594,357$ & $28,740,073$ & $2.0 \%$ & $0.5 \%$ \\
\hline
\end{tabular}

NIH budgets are compared by institute and center (IC) for FY 2004 to FY 2006 (US $\$$ in thousands). Other institutes in addition to the NIAID are presented for comparison: NCI, National Cancer Institute; NHLBI, National Heart, Lung and Blood Institute; NHGRI, National Human Genome Research Institute; NIDA, National Institute for Drug Abuse. NLM, National Library of Medicine; OD, Office of the Director; B\&F, Buildings and Facilities.

for advances in knowledge and the practical application of these advances will surely increase. Hence, the dichotomy between aspirations and resources will probably widen." 3

To make the best use of available resources and to limit the gap between aspirations and resources, a top-to-bottom examination of every NIH research portfolio was undertaken in the mid-1990s to prepare for the possibility of a substantial budget decrease; it was enlightening to see that there were many areas in which research could have been carried out more efficiently. Fortunately, the budget decreases we expected did not come to pass, thanks to a 'deus ex machina' in the form of advocacy efforts and congressional and administrative leadership, which resulted in the aforementioned doubling of the NIH budget $^{7}$. NIH-funded investigators, especially those in infectious diseases research, enjoyed substantial annual budget increases that helped facilitate important advances in pathogenesis, natural history, epidemiology, behavioral and social sciences, vaccine development and therapeutics ${ }^{5}$. Indeed, some younger investigators in the areas of HIV-AIDS and other infectious diseases have been fortunate to have worked their entire careers relatively unfettered by the fiscal constraints that have typified other eras in biomedical research funding. But as with other areas of NIH-funded research, infectious disease research, including the HIV-AIDS research 'portfolio', now faces the reality of a constrained level of funding; in HIV research, only HIV vaccine research is projected to see a substantial increase in FY 2006 (ref. 10). The selective increase in HIV vaccine research funding reflects the consensus that a safe and effective vaccine against HIV is essential to curbing the global HIV pandemic ${ }^{10,11}$.

Funding for biodefense research increased substantially after the 11 September 2001 attacks on the US and the subsequent bioterror events involving anthrax spores disseminated via the US mail. However, in the period of FY 2003 to FY 2006, NIH biodefense funding, like overall infectious diseases funding, has leveled off at a relatively constant amount of about $\$ 1.7$ billion. Notably, the examples of HIV-AIDS and biodefense are not typical of emerging and re-emerging diseases. Most infectious disease threats are perceived as seri-

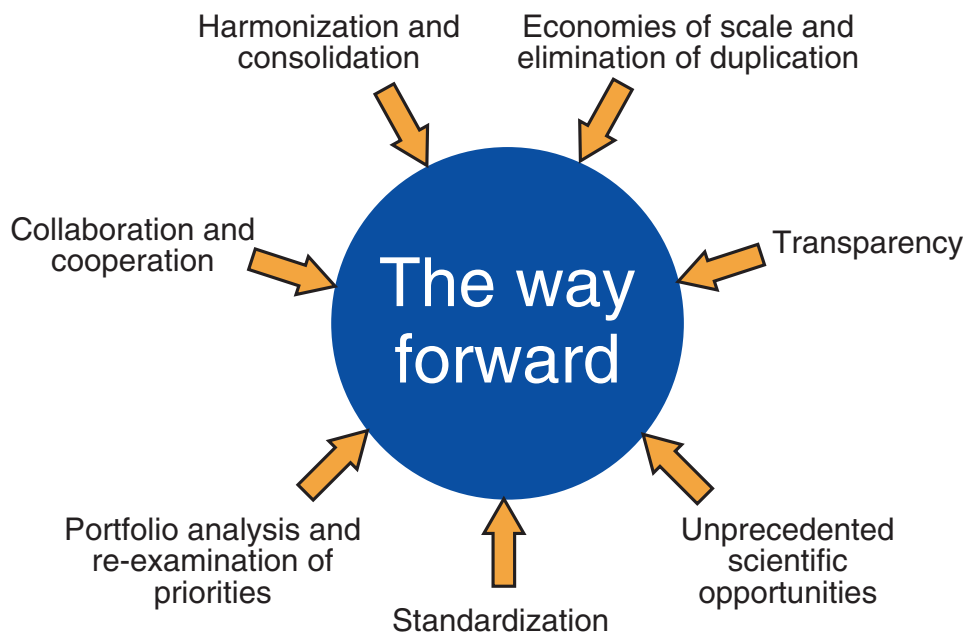

Figure 3 Necessary steps in infectious disease research in the present era of fiscal constraint. ous threats for a year or two (such as West Nile virus and SARS) and do not drive the budget in a significant and sustained way, compared with HIV-AIDS, a pandemic that rages out of control $^{1,2}$, and bioterrorism, which is perceived to be an 'indefinite' threat ${ }^{12}$. The substantial NIH funding base for biodefense, like that for HIV-AIDS, is likely to be maintained for the foreseeable future together with the funding base for infectious diseases in general.

\section{A new era of fiscal constraint}

Looking ahead to the NIAID budget beyond FY 2006, we anticipate annual budget increases of less than $2 \%$, annual increases in the cost 


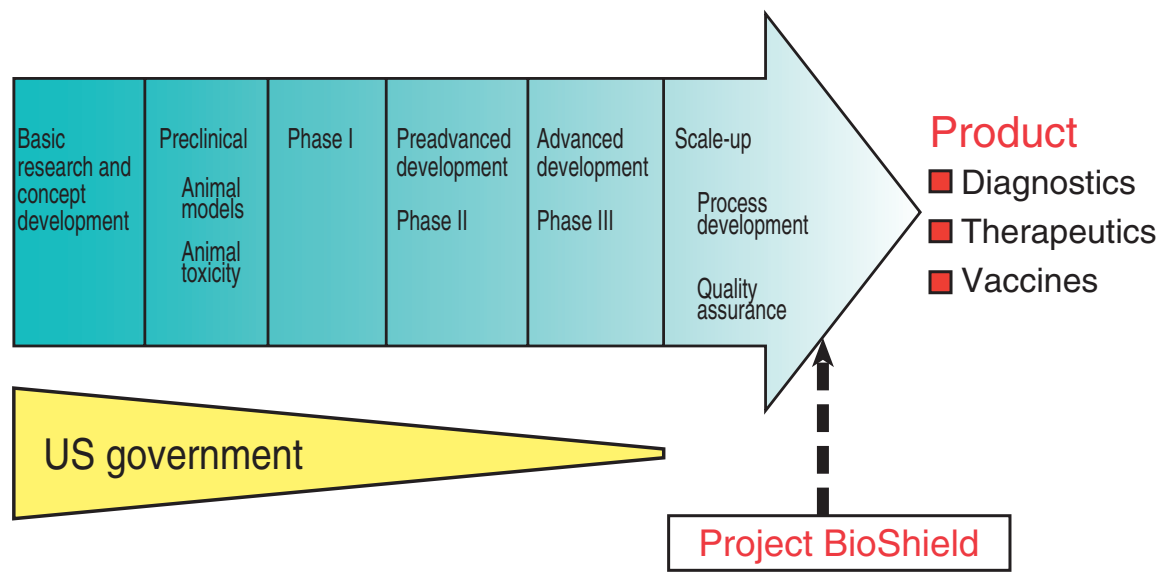

Figure 4 Research supported by the NIH has evolved to encompass an increased emphasis on advanced product development, in addition to the traditional NIH role of supporting basic, preclinical and early-stage clinical research.

of basic research grants (ROI grants) averaging 5\% and an annual increase in research project grant (RPG) applications of about $2 \%$ (ref. 8). An important challenge for the NIAID is to reconcile these numbers and find a way to preserve a robust commitment to the fundamental, investigator-initiated research that is the bedrock of the research enterprise while meeting expectations for more applied research, including the advanced development of vaccines, therapeutics and diagnostics ${ }^{8}$.

A key 'post-doubling' NIAID goal is to maintain a minimum base of 950 competing RPG awards each year. In FY 2004, the latest year for which final figures are available, NIAID funded more than 1,100 competing awards. Regardless of budget constraints, we feel that it is imperative not to fall below the threshold of 950 RPGs, to avoid 'turning off the faucet' of innovation fed by basic research. However, to maintain the level of 950 awards per year, we will need to take some unfamiliar measures. Almost certainly, the NIAID along with the NIH as a whole will no longer be able to provide investigators with yearly inflationary increases in their grant funding, and we may need to reduce the average dollar amount of new awards. In addition, success rates (that is, the proportion of grant applications that receive funding) will drop from about $24 \%$ in FY 2004 to about $18-19 \%$ in the period FY 2007 to FY 2009.

Of course, it remains essential that all of us in the medical and public health communities continue to argue cogently for adequate attention and sustained research support for all diseases of global health importance. The public health challenges facing us are substantial and the scientific opportunities for true breakthroughs abound. At the same time, we must collectively prepare for the difficult questions that are posed more and more frequently as policymakers and the public challenge what some perceive to be 'research entitlements' in well funded areas of inquiry such as HIVAIDS research. Such questions, asked during congressional hearings, meetings with administration officials and briefings of constituency groups include the following: how are you spending the large bolus of money you already have received; how do you set your priorities; can you accomplish even more by increasing efficiencies; and-perhaps most salient-is your research yielding products that benefit the health of the American people? In today's budget environment, the administration, congress and the public expect us to continually examine the research enterprise; in other exempt from scrutiny and review.

I am frequently asked, in my role as the head of the NIH institute with the largest portion of the HIV-AIDS research portfolio, whether HIV-AIDS funding will be cut, especially given the fact that this disease occupies fully one third of the NIAID budget. The answer is almost certainly no, given the recognition by those at the White House, by members of congress on both sides of the aisle and by the general public that HIV-AIDS is a plague of historic proportions ${ }^{4}$. Certainly, cuts in HIV-AIDS funding will not be part of NIAID strategic planning 8 . However, with HIV-AIDS and other infectious diseases, we will need to make the best of available funding by re-examining how we do business. Several necessary steps must be taken (Fig. 3). First, we must strive for more collaborations and better cooperation among investigators in government, industry, academia and philanthropic organizations, with an eye toward words, there can be no 'sacred cows' that are 'harmonization' and improving economies of scale. In many infectious disease disciplines, we can probably eliminate redundancy in our clinical trials networks. We also must standardize assays, reagents and endpoints such that results of investigations are broadly relevant to an entire field, rather than to only the subset of research groups that have chosen a particular set of parameters ${ }^{11}$. It also is imperative that we eliminate unnecessary duplication in the research enterprise to the extent possible. Many times duplication is very important and indeed necessary to confirm research findings, but unnecessary duplication is unacceptable in a time of fiscal constraint.

To maximize finite resources at a time when our scientific aspirations and opportunities are nearly infinite, infectious disease investigators in government, academia and industry must by necessity collaborate if useful medical countermeasures are to reach the market. No one sector can single-handedly address the complex scientific, technical, social, economic and political challenges involved in product development ${ }^{13}$. With cross-sector collaborations, extraordinary successes have been achieved, including all recently licensed vaccines and the more than 20 antiretroviral medications now available $e^{1,2,13}$.

\section{Striking a balance}

As noted above, we are facing an increased expectation for 'deliverables' and the challenge of balancing basic research with advanced product development in the setting of fiscal constraint. Throughout my scientific training I was taught, and I still believe, that there is an important place for 'scientia gratia scientiae' (science for the sake of science) in the scientific endeavor. Fundamental research driven by a scientist's curiosity or interest in a scientific question will always be a central tenet of scientific inquiry. Even a cursory look at the history of biomedical research reminds us that some of our most important scientific breakthroughs have invariably been achieved through openended inquiry.

The NIAID has always supported both fundamental research that generates new knowledge about disease while working to translate these findings into vaccines, therapeutics and diagnostics that protect public health ${ }^{8}$. However, to rapidly develop safe and effective products, we have been asked by the government that provides our funding to intensify and accelerate this process. We cannot do this at the expense of our basic research 'portfolio'. Thus, we have sought creative ways to modify the traditional processes of research and development to move more rapidly ahead while continuing to preserve the excellence in basic research that 
is a hallmark of the NIH. Working in close collaboration with industry and academia, we have taken a much more proactive role in moving promising ideas into advanced product development. For example, the Project BioShield Act of 2004 provides powerful new mechanisms that will expedite the development and deployment of medical countermeasures for bioterrorism (ref. 14 and Department of Health and Human Services, Project BioShield, http://www. os.dhhs.gov/ophep/bioshield/). BioShield gives the NIH additional flexibility in awarding contracts, cooperative agreements and grants for research and development for critical medical countermeasures and streamlines the scientific evaluation of biodefense research proposals. Bioshield also provides industry with assurances that markets for their products will exist should they invest the resources necessary to fully develop them. To help provide these incentives, BioShield establishes a secure 10-year funding source for the purchase and stockpiling of new vaccines and drugs for use in an emergency. Thus, BioShield has given us new ways to both 'push' and 'pull' science toward needed countermeasures: basic research provides the push, and new incentives to industry for product development provide the pull.

Project BioShield may represent a new model for enticing industry to participate in developing products for which a profitable market is not assured and is emblematic of a broader shift in the role of the NIH in advanced product development. Increasingly, the NIH and 응 NIAID are expanding their roles beyond traditional areas of basic, preclinical and small-scale research into advanced product development using mechanisms such as vaccine production contracts and new partnership programs ${ }^{8}$ (Fig. 4). This approach transcends HIV-AIDS and biodefense and can apply to countermeasures for a broad range of infectious diseases. In this context, the NIAID Vaccine Research Center has proven to a be an extraordinarily successful model, developing vaccines against pathogens such as HIV, the SARS coronavirus, smallpox virus and West Nile virus, taking ideas from basic research to the production of 'pilot lots' to the conduct of clinical trials (National Institute of Allergy and Infectious Diseases. Dale and Betty Bumpers Vaccine Research Center, http://www.niaid.nih.gov/ $\mathrm{vrc} /$ ). The NIAID also has bolstered its 'portfolio' of research resources that are provided to academic and industrial partners to 'prime the pump' of product development. These research resources are managed by the institute's extramural research divisions (Division of Allergy. Immunology and Transplantation, http://www. niaid.nih.gov/research/dait.htm; Division of Acquired Immune Deficiency Syndrome, http://www.niaid.nih.gov/daids/; Division of Microbiology and Infectious Diseases, http:// www.niaid.nih.gov/dmid/) and include reagent repositories, genomic databases, animal models, clinical trials support and other resources.

New models of collaboration promise to optimize the search for critical countermeasures by enhancing coordination and information sharing and collaboration. The Global HIV Vaccine Enterprise, a 'virtual' consortium or network of collaborating institutions, has been established to prioritize the scientific challenges to be addressed in HIV vaccine development and to fill in the gaps that are identified ${ }^{11}$. This enterprise seeks to stimulate both researchers and those funding research to explore new, more collaborative, cooperative and transparent approaches to address the main obstacles in HIV vaccine development, in addition to continuing the productive, highquality programs already underway. In another example, the NIAID will restructure its AIDS clinical trials networks to maximize scientific opportunities. This will be accomplished by integrating prevention and treatment research, improving efficiencies, building and strengthening research capacity, especially in resourcelimited settings, and improving accountability and evaluation methods (Division of AIDS Clinical Trials Network FY 06, http://www. niaid.nih.gov/daids/rfa/network06/).

\section{Conclusion}

The reality of steady-state funding for infectious disease research is one that we must face collectively. We enjoy unprecedented scientific opportunities because of the successes of our previous and present endeavors. To make the most of these opportunities in a time of fiscal constraint, we must rigorously examine and reanalyze our research portfolios and strive for increased transparency, standardization, collaboration and harmonization, greater economies of scale, and less unnecessary redundancy. In a world expecting 'deliverables', we must push for tangible results (products) without compromising our greatest asset: the individual creativity of our basic research investigators.

\section{ACKNOWLEDGMENTS}

Based on a lecture presented at the $12^{\text {th }}$ Conference on Retroviruses and Opportunistic Infections 23 February 2005 (Boston, Massachusetts). The author thanks G.K. Folkers for discussions related to the preparation of the manuscript and the lecture on which it was based.

1. Morens, D.M., Folkers, G.K. \& Fauci, A.S. Nature 430 242-249 (2004).

2. Rappuoli, R. Nat. Med. 10, 1177-1185 (2004).

3. Fauci, A.S. Lancet 348, 1002-1003 (1996).

4. Folkers, G.K. \& Fauci, A.S. J. Am. Med. Assoc. 286 458-461 (2001).

5. Fauci, A.S. Nat. Med. 9, 839-843 (2003).

6. Office of Management and Budget. Budget of the United States Government, Fiscal Year 2006 (http:// www.whitehouse.gov/omb/budget/fy2006).

7. Malakoff, D. Science 292, 1992-1995 (2001).

8. National Institute of Allergy and Infectious Diseases. Fiscal Year 2006 (President's Budget; http://www. niaid.nih.gov/budget/fy06.pdf).

9. NIH Office of Science Policy and Planning. BRDPI Overview of Annual Budget (http://ospp.od.nih.gov/ ecostudies/brdpi_fy2004.asp).

10. National Institutes of Health. Office of AIDS Research, NIH Fiscal Year 2006 Plan for HIV-Related Research (http://www.nih.gov/od/oar/public/pubs/fy2006/00_ Overview_FY2006.pdf).

11. Coordinating Committee of the Global HIV/AIDS Vaccine Enterprise. PLoS Med. 2, 111-121 (2005).

12. Atlas, R.M. Annu. Rev. Microbiol. 56, 167-185 (2002).

13. Folkers, G.K. \& Fauci, A.S. Nat. Med. 4, 491-494 (1998).

14. Fauci, A.S. Nature 421, 787 (2003). 